\title{
Managing Patient Pressure to Prescribe Antibiotics in the Clinic
}

\author{
Tanya Stivers ${ }^{1}[0$
}

Accepted: 4 August 2021 / Published online: 19 August 2021

(c) The Author(s), under exclusive licence to Springer Nature Switzerland AG 2021

\begin{abstract}
Acute respiratory tract infections (ARTIs) are typically viral; however, in the USA, approximately one-third of adults and $52 \%$ of children with ARTIs receive an antibiotic, making antibiotic prescribing for ARTIs a major contributor to the problem of inappropriate prescribing. Relying on a synthesis of work across pediatric and adult primary care, this article shows some of the main ways that patients and parents pressure physicians for antibiotics, whether intentionally or unintentionally, and how physicians combat that pressure. All data are from video recordings of community-based clinical encounters allowing us to see what is happening "on the ground." Strategies that physicians actually use are documented; however, untutored physicians do not rely on these reliably or strategically, leaving substantial room for the deployment of a three-pronged communication strategy that can reduce patient pressure and inappropriate antibiotic prescribing.
\end{abstract}

\section{Background}

Acute respiratory tract infections (ARTIs) are typically viral; however, in the USA, approximately one-third of adults and $52 \%$ of children with ARTIs receive an antibiotic [1-4]. For instance, although only $18 \%$ of adult patients with complaints of sore throat have a positive test for the relevant Streptococcus bacteria, $72 \%$ of these receive antibiotics [1]. Similarly, just $2 \%$ of adults aged 20-64 years with sinus infection symptoms reach the threshold where they should be given antibiotics, but $55 \%$ of patients receive them [1]. The same pattern is found in pediatrics. Although overall bacterial prevalence is estimated at $27 \%$, over half of visits result in antibiotic prescriptions [4]. ARTIs account for 120 million adult ambulatory medical visits [5] and some 25 million pediatric visits each year [4].

Why does inappropriate prescribing of antibiotics persist? Physicians tend to cite patient demand for antibiotics [6-8]. Although research in pediatric visits has shown that explicit requests or "demands" are rare [9], parents' other behavior influences whether or not their children receive antibiotics. For instance, when parents offer a bacterial diagnosis as a likely cause of their children's illnesses (a candidate diagnosis), physicians are more likely to report that they perceived parents as expecting antibiotics in their encounter, thus

Tanya Stivers

stivers@soc.ucla.edu

1 Department of Sociology, UCLA, Los Angeles, CA, USA

\section{Key Points}

Patients with Acute Respiratory Infections rely on communication practices that, whether intentionally or unintentionally, pressure physicians to inappropriately prescribe antibiotics.

Physicians can effectively address pre-diagnostic pressure by foreshadowing a non-antibiotic treatment outcomes while they can reduce resistance to non-antibiotic treatment with affirmatively designed counseling.

Physicians naturally relied on these practices showing that they are easy to use, but their frequency and strategic use can be improved making them important tools for combatting subtle patient pressure for antibiotics.

treating it as a subtle form of pressure [10]. When parents question a viral illness diagnosis or a nonantibiotic treatment recommendation, this too is treated as a form of pressure ("resistance") and is associated with physicians reporting parents as expecting an antibiotic prescription [10].

Decades of efforts to educate physicians, parents, and patients has moved the needle of overprescribing but not far enough. Prescribing rates remain high and-after some decreases-are plateauing again [11-13]. The Centers for Disease Control and Prevention (CDC) continue to rely on education as their primary tool to overcome pressure, with 
the assumption that patients will behave rationally: if they understood the problem, they would not pressure their physicians. Moreover, their efforts to lower prescribing rests on the idea that if physicians understood, they would not overprescribe [14]. Unfortunately, this view of the overprescribing problem underestimates the highly social and contingent nature of antibiotic prescribing. Communication-based strategies are more effective [15]. I propose a three-pronged communication strategy that partly overlaps with that proposed by Mangione-Smith and her colleagues, can easily be implemented, and stands to reduce inappropriate prescribing for ARTIs in children and adults alike [15].

I argue that patient pressure differs according to when it happens during a clinic visit: either before the diagnosis or after a diagnosis or treatment recommendation. Physicians' communicative resources to address patient pressure also differ according to these early and late positions. These communicative tools address calls for new and more varied physician communication resources to manage perceived patient pressure for antibiotics [16].

\section{Approach}

To offer a coherent evidence-based strategy for reducing conflict and inappropriate antibiotic prescribing, I synthesize findings from recent published work on adults in primary care and other published work on children being seen in routine pediatric visits. Adult data were drawn primarily from two corpora of video recordings of primary care consultations that occurred in southern California, USA. One corpus was collected between 2003 and $2004(n=54)$, and another was collected from 2015 to $2016(n=14)$. The data sets involved convenience samples of patients being seen for acute care issues (the 2003-2004 sample) or unrelated chronic illnesses (2015-2016 sample). Following early analyses to assess whether antibiotic usage or their related communication practices showed no difference, the samples were combined.

The pediatric corpus was also collected in southern California, USA, and comprised approximately 520 visits for ARTIs collected between 2000 and 2001. All participants provided written consent in accordance with the relevant university institutional review board requirements. The core adult encounters involved a total of 30 primary care providers, and the pediatric encounters involved 38 providers, nearly all pediatricians. All were located in communitybased clinics.

In the studies I drew upon, inappropriate prescribing was generally identified as the provision of a viral diagnosis or an indication of no bacterial illness along with an antibiotic prescription. If no specific diagnosis was provided but clinical findings were reported, I also relied on CDC guidelines from the time of the visit to identify any symptoms that were indicative of bacterial infection and antibiotic treatment. If a physician at any time indicated a clinical sign as indicative of bacterial infection, an antibiotic prescription was identified as appropriate.

Findings presented here relied on a mix of conversation analysis as a qualitative method, descriptive statistics, and the $\chi^{2}$ test of independence to assess statistical significance in bivariate relationships between communication practices and between communication and prescribing practices. Conversation analytic work did not rely on specific software. For a review of conversation analysis in clinical encounters see Gill and Roberts [17].

\section{Findings}

In 37\% (25/68) of adult cases, clinicians prescribed antibiotics in the absence of clinical signs [18]. In $16 \%$ of pediatric cases, clinicians prescribed antibiotics for illnesses they reported as viral (41/260) [19]. Although studies point to exogenous factors that contribute to overprescribing, including decision fatigue [20] or the hope that patients do not return to the clinic for the same illness [21], I focus on how patient pressure contributed to the problem.

I begin with a discussion of how patients intentionally or unintentionally conveyed pressure for antibiotic treatment to clinicians; I then explore how clinicians responded to patients, including communication strategies that were effective in combating patient pressure, regardless of intention.

Table 1 Phases of the acute care medical visit

\begin{tabular}{lll}
\hline Visit phase & Patient pressure & Physician strategy \\
\hline Opening & Priming & Foreshadowing \\
Establishing the problem & Priming & Foreshadowing \\
Information gathering & Nudging & Foreshadowing \\
Counseling & Resistance & Affirmative presentation and persuasion \\
Closing & Resistance & Affirmative presentation and persuasion \\
\hline
\end{tabular}




\subsection{Pressuring During the Consultation}

Bookended by opening and closing sequences, we can think of the acute care medical visit as proceeding through several phases [22]. These include "problem identification," in which patients volunteer or physicians solicit patients' reasons for visiting; "information gathering," during which clinicians take verbal histories and conduct physical examinations; and "counseling," during which they discuss diagnosis and treatment. As summarized in Table 1, during each phase, patients have structurally provided opportunities to steer physicians towards bacterial diagnoses and antibiotic treatments, but physicians also have opportunities to manage their expectations away from antibiotics and to persuade them to accept a viral diagnosis and symptomatic treatment. I discuss patient pressure practices in the prediagnosis and postdiagnosis positions before turning to physician strategies for quelling this pressure.

\subsubsection{Prediagnosis Negotiation}

Priming for antibiotics occurs when patients describe problems in ways that are relevant to bacterial illness prior to physicians taking a position on the issue [18]. This is done most commonly with candidate diagnoses [10] or extreme characterizations of symptoms. These practices not only justify seeing the physician for an illness [23] but also introduce the need for stronger treatment. In the context of ARTIs, this is nearly always understandable as pressure for antibiotics.
We can see examples of priming taken from the data in Table 2 contrasted with a nonpressuring way that patients bring up the same symptoms.

With priming practices, patients initiate pressure without necessitating physicians' uptake. Although physicians do not need to provide a response, patients' actions nonetheless provide "help" for physicians to see patients' problems as severe, bacterial, and in need of antibiotics compared with neutrally listing symptoms in the presentation.

During history taking and physical examination, patients do not always simply answer questions. Instead, they may introduce additional information, nudging physicians towards or away from diagnoses [24]. Nudging usually occurs when patients answer a question or when they broach a new topic at this juncture [18]. We can see a series of examples from the data in Table 3. In all cases, patients mark the added information as relevant for physicians' consideration and use their answer turns to redirect clinicians towards bacterial or antibiotic-relevant symptoms. Although patients may incorrectly believe that a given symptom is indicative of a bacterial infection, the pressure is nonetheless apparent.

Priming and nudging are forms of pressure that occur prediagnosis. This pressure has a statistically significant association with inappropriate prescribing. Early pressure leads to prescribing in the absence of clinical signs in $60 \%$ of adult cases. When patients do not exercise this early pressure, physicians prescribe without clinical signs only $30 \%$ of the time $\left[\chi^{2}(1)=4.85 ; p<0.05\right]$.

Table 2 Priming pressure

\begin{tabular}{ll}
\hline No pressure descriptions & Priming for bacterial infection $(47 \%$ of adult cases, $n=32)$ \\
\hline "Sore throat" & "It's like a knife" \\
"Bad cough" & "My cough is terrible" or "I cough so hard I throw up" \\
"Runny nose" & "Tons of green mucus" \\
"Sore throat" or "nasal congestion" or "cough" & "Strep throat" or "sinusitis" or "pneumonia" \\
— & "I'm on a panel of judges ... and we've been listening ... and I'm sitting \\
& there ... just blowing my nose every five minutes ... I've gone through \\
& boxes of Kleenex" \\
\hline
\end{tabular}

Table 3 Nudging pressure

\begin{tabular}{ll}
\hline No pressure & Nudging for bacterial infection (41\% of adult cases; $n=28)$ \\
\hline "How's the nose?" "It's runny" & $\begin{array}{c}\text { "Does it [ear pain] stay just in that area? Does it go anywhere else?" "No it's only } \\
\text { in my left ear and I'm flying to Chicago [on] Wednesday, and I know that } \\
\text { altitude could be a problem with ear things" } \\
\text { "You're taking some Sudafed?" "I took all that stuff and nothing did anything" }\end{array}$ \\
$\begin{array}{ll}\text { "Do you have a history of allergies. Hay fever." "A little, it } \\
\text { doesn't bother me a great deal, but" }\end{array}$ \\
$\begin{array}{ll}\text { "Not having any shortness of breath, chest pain, wheezing, or } \\
\begin{array}{l}\text { anything like that?" "No." } \\
\text { Listening to lungs: "I don't hear any wheezing" }\end{array}\end{array}$ & \begin{tabular}{l} 
Patient response: "I can feel it rumbling" \\
\hline
\end{tabular}
\end{tabular}


Table 4 Resistance as pressure

\begin{tabular}{ll}
\hline Physician assertion & Resistance (22\% of adult cases; $n=15)$ \\
\hline "Gosh your throat really doesn't look like a strep throat though" & "No?" \\
"There's no pus or any ..." & "It was earlier ... there was pus (.) yesterday" \\
$\begin{array}{l}\text { Doctor told patient that it's a virus and won't respond to antibiotics. } \\
\text { Body will fight it by itself. Recommended Sudafed or a combination } \\
\text { of Sudafed and Robitussin }\end{array}$ & $\begin{array}{c}\text { Patient offers no uptake during lengthy counseling. Then when physi- } \\
\text { cian asks, "questions?" he says, "No I just wanted to see if I could get } \\
\text { something ... help me out a little" }\end{array}$ \\
\hline
\end{tabular}

\subsubsection{Postdiagnosis Negotiation}

Returning to Table 1, when physicians give their diagnoses and/or treatment recommendations, patients are provided with another opportunity to influence the visit outcome. At this moment, physicians reveal their stances towards the patient's illness as either viral or bacterial, warranting symptomatic treatment or antibiotics. Once physicians provide an assessment, any patient response that questions or contests a clinician's recommendation for nonantibiotic treatment constitutes active patient resistance [25]. Resistance practices vary from querying an examination finding to indicating that over-the-counter treatments have been ineffective in the past. A series of examples from the data are shown in Table 4.

Although, in principle, patient resistance could be related to many types of medications, in the context of ARTIs, resistance to nonantibiotic recommendations is nearly always a form of lobbying for antibiotics (or their associated bacterial diagnoses). In the adult data, I found only one case of resistance to an antibiotic treatment. The patient justified her resistance with reference to prior yeast infections.

Parent resistance has been found to be a powerful form of pressure for antibiotics [10, 19]. In the pediatric data, resistance was a significant predictor of physicians perceiving parents as expecting antibiotics, leading physicians to be $32 \%$ more likely to inappropriately prescribe antibiotics [19]. Although resistance in the adult data was not significantly associated with inappropriate prescribing, it was less common than prediagnostic forms of pressure, which reduced the power to identify a statistical association. Additionally, I still observed that physicians altered their treatments in $60 \%$ of cases involving resistance $(n=$ 9 ). In some cases, they added additional tests or nonantibiotic treatment. In three of the cases, they added an antibiotic. Without resistance, physicians did not alter their treatments.

\subsection{Responding to Pressure}

As summarized in Table 1, patients pressure physicians at two main junctures: prediagnosis and postdiagnosis. These different positions entail different physician communication strategies if they are to effectively reduce and combat pressure over the course of the visit. I advocate for a three-prong communication strategy:

1. Foreshadowing a likely viral or symptomatic treatment plan

2. Affirmative counseling for viral diagnoses/nonantibiotic plans

3. Persuasion when facing patient resistance

As shown in Table 1, foreshadowing a likely viral diagnosis and symptomatic treatment plan is a communication strategy that physicians can rely on during the phases of the visit up to diagnosing. In contrast, providing affirmative diagnostic and treatment plans is specific to delivering those recommendations. Persuading is a communication strategy that physicians can rely on when the diagnosis and treatment plans have been conveyed but they are still facing resistance.

\subsubsection{Foreshadowing}

Most physicians offer patients the floor to characterize their reason for the visit rather than first articulating an understanding based on notes in the patient's chart [26]. If patients used pressuring terms and descriptions to prime the visit or answered physicians' questions with antibiotic-relevant nudges, physicians in these data sometimes responded in ways that would manage patients' expectations away from antibiotics. Some common ways are summarized in Table 5 [27, 28].

Table 5 Foreshadowing strategies

\begin{tabular}{|c|c|}
\hline Foreshadowing strategies & Examples \\
\hline Deflecting & "Let me take a look" \\
\hline Online commentary & $\begin{array}{l}\text { During examination: "There's } \\
\text { no pus" "The lungs are clear' } \\
\text { "There's no white spots" }\end{array}$ \\
\hline Diagnostic projections & $\begin{array}{l}\text { "That can be a symptom of a } \\
\text { viral infection" "Typically } \\
\text { they're viruses that do this to } \\
\text { people" }\end{array}$ \\
\hline
\end{tabular}


All of these strategies still allow for physicians to find a bacterial infection during the examination and then to diagnose and prescribe accordingly. However, commonly, physicians find no clinical signs consistent with bacterial infection but are under pressure from patients to prescribe. When physicians managed patients' expectations away from antibiotics through foreshadowing in these ways, they were significantly less likely to inappropriately prescribe antibiotics. In the adult sample, physicians prescribed $33 \%$ of the time compared with 59\% when they did not manage expectations through foreshadowing $\left[\chi^{2}(1)=3.65, p=0.056\right]$ [18].

Managing expectations also reduced the rate of patient resistance to viral diagnoses or nonantibiotic treatment recommendations. Despite a non-statistically significant trend, patients resisted half as often when clinicians engaged in expectation management [ 16 vs. $30 \%$ of the time; $\chi^{2}(1)=$ $1.97 ; p=0.16]$, suggesting that managing patient expectations before the diagnosis may disarm postdiagnosis pressure for antibiotics.

\subsubsection{Affirmative Counseling}

When physicians recommend symptomatic nonantibiotic treatment, they can deliver that information affirmatively (what can be done) or negatively (what cannot or will not be done). Table 6 offers some examples from the data.

Physicians rely on both types of recommendations [19, $25,29]$. In prior analyses in pediatrics, affirmatively formatted recommendations were consistently less likely to be resisted $[19,25,29]$. In the adult data too, among cases with no clinical signs of bacterial infection, when physicians began with affirmative treatment recommendations, patients resisted only $18 \%$ of the time compared with $55 \%$ of the time when physicians began with negative recommendations $\left[\chi^{2}(1)=5.71 ; p<0.05\right]$. By lowering rates of resistance, the likelihood that physicians will modify the treatment plan and prescribe inappropriately is also reduced.

\subsubsection{Persuasion}

During the counseling phase, most patients accept physicians' recommendations, including those for nonantibiotic treatments. Yet, when facing resistance, physicians commonly work to gain patient acceptance by persuading. Persuasion can involve explaining why a physician believes that a viral diagnosis and symptomatic treatment are appropriate or offering nonantibiotic accommodations or concessions [30]. Examples of persuasion are shown in Table 7.

Table 6 Recommendation strategies

\begin{tabular}{ll}
\hline Recommending strategies & Examples \\
\hline Affirmative & $\begin{array}{l}\text { "There's a medication that'll take care of it called Actifed" } \\
\text { "You have some fluid pushing on the inner lining of your left ear, and I think that's what's causing the } \\
\text { problem. And so I'm going to put you on some medicine to try and dry that out and take away } \\
\text { the pressure ..." } \\
\text { "Most of what we get are viral infections. They don't respond to antibiotics" "Antibiotics don't help" }\end{array}$ \\
\hline
\end{tabular}

Table 7 Persuasion strategies

\begin{tabular}{|c|c|}
\hline Persuasion strategies & Examples \\
\hline Accounting for the viral diagnosis & $\begin{array}{l}\text { "I think you have a viral infection right now, because you don't have the high fever, because your } \\
\text { throat looks pretty good, and because your ears look pretty good, and your lungs sound } \\
\text { pretty good. Those are all areas where you get a bacterial infection" } \\
\text { "The throat is red, but you also have a lot of cobble-stoning in the back of your throat, and } \\
\text { that's a sign of postnasal drip. Okay, and that's what's causing your sore throat" }\end{array}$ \\
\hline Accounting for the nonantibiotic treatment & $\begin{array}{l}\text { "I'm going to put you on some medicine to try and dry that [ear] out and take away the pres- } \\
\text { sure, and that should make it fairly comfortable for you to fly" } \\
\text { "Most of the time they're a virus. And also, you have some complement of allergy. I saw some } \\
\text { swelling of your nasal mucosa. So, I'm going to treat you right now for symptomatic treat- } \\
\text { ment unless the culture comes back positive ... right now, I will just give you symptomatic } \\
\text { treatment. Some cough medications, some anti-allergy medications, and a nose spray" }\end{array}$ \\
\hline Accommodations/concessions & $\begin{array}{l}\text { "Since you're here I'm gonna do a throat culture" "Since you're leaving the country, I might } \\
\text { do the x-ray" Following resistance, doctor adds Claritin-D: "It contains pseudoephedrine, which } \\
\text { is what you're using as a good decongestant. So, it's also got antihistamine in combination with a } \\
\text { decongestant, so it should work more effectively than a single-action medication" }\end{array}$ \\
\hline
\end{tabular}


Persuasion strategies, like foreshadowing strategies, are associated with reduced rates of inappropriate prescribing. When physicians engaged in these strategies, they prescribed antibiotics in the absence of bacterial clinical signs only $33 \%$ of the time compared with $63 \%$ of the time when facing pressure and not using persuasion $\left[\chi^{2}(1)=4.56 ; p<0.05\right]$ [18]. This suggests that persuasion helps to secure patient acceptance, letting physicians close more visits without prescribing antibiotics.

\subsection{Physicians' Natural Use of These Strategies}

The strategies of foreshadowing, affirmative counseling, and persuasion all emerged from observing what physicians intuitively relied on in the face of patient pressure. However, physicians' untutored reliance on these strategies was limited. No physician relied on these practices systematically. Physicians in these data inconsistently foreshadowed viral diagnoses and nonantibiotic treatment and were no better than chance in embracing it to head off early pressure $\left[\chi^{2}(1)=0 ; p=1.0\right]$. They relied on counseling strategies more often, using affirmative recommendations $78 \%$ of the time when recommending against antibiotics with no clinical signs $(n=38)$, and they relied on persuasion practices $53 \%$ of the time when patients resisted a viral diagnosis or nonantibiotic recommendation versus only $5 \%$ of the time in cases where patients had not resisted $\left[\chi^{2}(1)=16.23 ; p<\right.$ $0.001]$. This leaves significant room for the strategic use of these practices to effectively reduce pressure and inappropriate prescribing.

\section{Discussion and Implications}

Inappropriate antibiotic prescribing for ARTIs is one of the least tractable US public health problems. Studies relying on the National Ambulatory Medical Care Survey from 1989 to 2015 examining antibiotic prescribing trends revealed ongoing and serious amounts of overprescribing across primary care [31-33]. Although reductions have occurred in pediatrics, the trend is flat for adults [13]. Aside from the effects of mitigation measures related to the coronavirus disease 2019 pandemic in reducing prescribing by reducing the occurrence of other illnesses [34], the progress in solving this problem has been relatively small, especially considering how widespread the efforts have been.

Our inability to stem rampant inappropriate antibiotic prescribing may lie in our consistent underestimation of the deeply social nature of our problem. In line with prior research, I showed that patient communication with physicians matters for treatment outcomes. Patients use communication strategies that, although not explicit, are consistently understood as pressuring them to prescribe antibiotics. Not all patients pressure physicians for antibiotics (purposefully or inadvertently), but when patients do apply pressure, even subtly, it can start as early as the beginning of the consultation and can persist through each phase of the visit.

This paper does not present the results of an intervention. However, it offers similar evidence in the form of a natural experiment because clinicians spontaneously rely on the behaviors part of the time, allowing us to examine patterns with and without the target behavior. In this paper, I showed that these communicative practices could be used more systematically to combat pressure and reduce overprescribing. I also showed that, just as pressure takes different forms at different points in the visit, communication strategies to combat pressure must be tailored to those phases. Patients and physicians alike play critical roles in the persistence of the current antibiotic crisis. Although physicians tend to blame patient demand for antibiotic overprescribing, physicians remain the ultimate gatekeepers to antibiotic prescriptions. Thus, more effective communication may mitigate the crisis. We might wish that antibiotic prescriptions were not the result of physician-patient negotiations, but denying this reality has already cost us critical time in preserving antibiotics as effective treatments for infections.

Acknowledgements A version of this paper was presented at the European Society for Pediatric Infectious Diseases held virtually from Rotterdam in October 2020. The basis for this paper was developed in collaboration with Stefan Timmermans.

\section{Declarations}

Funding No sources of funding were used to conduct this study or prepare this manuscript.

Conflict of interest Tanya Stivers has no conflicts of interest that are directly relevant to the content of this article.

Ethics approval All data collection procedures were approved by the relevant university IRB.

Consent to participate All participants (patient/parents and clinicians) gave written informed consent.

Consent for publication Not applicable.

Availability of data and material Not applicable.

Code availability Not applicable.

Author contributions TS was responsible for all aspects of the creation of this article. 


\section{References}

1. Fleming-Dutra K, Hersh AL, Shapiro D, Bartoces M, Enns EA, File TM Jr, et al. Prevalence of inappropriate antibiotic prescriptions among US ambulatory care visits, 2010-2011. J Am Med Assoc. 2016;315(17):1864-73.

2. Ebel MH, Radke T. Antibiotic use for viral acute respiratory tract infections remains common. Am J Manag Care. 2015;21(10):e567-75.

3. Fauci AS, Marston ID. The perpetual challenge of antimicrobial resistance. J Am Med Assoc. 2014;311(18):1853-4.

4. Kronman MP, Zhou C, Mangione-Smith R. Bacterial prevalence and antimicrobial prescribing trends for acute respiratory tract infections. Pediatrics. 2014;134:e956.

5. Renati S, Linder JA. Necessity of office visits for acute respiratory infections in primary care. Fam Pract. 2016;33(3):312-7.

6. Sanchez GV, Roberts RM, Albert AP, Johnson DD, Hicks LA. Effects of knowledge, attitudes, and practices of primary care providers on antibiotic selection, United States. Emerg Infect Dis. 2014;20(12):2041-7.

7. Barden LS, Dowell SF, Schwartz B, Lackey C. Current attitudes regarding use of antimicrobial agents: results from physicians' and parents' focus group discussions. Clin Pediatr. 1998;37:665-72.

8. Watson RL, Dowell SF, Jayaraman M, Keyserling H, Koczak M, Schwartz B. Antimicrobial use for pediatric upper respiratory infections: reported practice, actual practice and parent beliefs. Pediatrics. 1999;104(6):1251-2157.

9. Stivers T. Participating in decisions about treatment: overt parent pressure for antibiotic medication in pediatric encounters. Soc Sci Med. 2002;54(7):1111-30.

10. Stivers T, Mangione-Smith R, Elliott MN, McDonald L, Heritage J. Why do physicians think parents expect antibiotics? What parents report vs what physicians perceive. J Fam Pract. 2003;52(2):140-8.

11. Vaz LE, Kleinman KP, Raebel MA, Nordin JD, Lakoma MD, Dutta-Linn MM, et al. Recent trends in outpatient antibiotic use in children. Pediatrics. 2014;133(3):375-85.

12. Centers for Disease Control and Prevention. Outpatient antibiotic prescriptions-United States; 2018.

13. King LM, Bartoces M, Fleming-Dutra K, Roberts RM, Hicks LA. Changes in US outpatient antibiotic prescriptions from 20112016. Clin Infect Dis. 2020;70(3):370-7.

14. Sanchez GV, Fleming-Dutra KE, Roberts RM, Hicks LA. Core Elements of outpatient antibiotic stewardship. Recomm Rep. 2016;65(6):1-12.

15. Kronman MP, Gerber JS, Grundmeier RW, Zhou C, Robinson JD, Heritage $\mathrm{J}$, et al. Reducing antibiotic prescribing in primary care for respiratory illness. Pediatrics. 2020;146(3):e20200038.

16. Cabral C, Horwood J, Hay AD, Lucas PJ. How communication affects prescription decisions in consultations for acute illness in children: a systematic review and meta ethnography. BMC Fam Pract. 2014;15:63.

17. Gill VT, Roberts F. Conversation analysis in medicine. In: Sidnell J, Stivers T, editors. The handbook of conversation analysis. Malden: Wiley-Blackwell; 2013. p. 575-92.

18. Stivers T, Timmermans S. Arriving at no: patient pressure to prescribe antibiotics and physicians' responses. Soc Sci Med. 2021. https://doi.org/10.1016/j.socscimed.2021.114007.
19. Mangione-Smith R, Elliott MN, Stivers T, McDonald LL, Heritage J. Ruling out the need for antibiotics: are we sending the right message? Arch Pediatr Adolesc Med. 2006;160:945-52.

20. Linder JA, Doctor JN, Friedberg MW, Nieva HR, Birs C, Meeker $\mathrm{D}$, et al. Time of day and the decision to prescribe antibiotics. JAMA Intern Med. 2014;174(12):2029-31.

21. Tonkin-Crine S, Yardley L, Little P. Prescribing for acute respiratory tract infections in primary care: a systematic review and meta-ethnography. J Antimicrob Chemother. 2011;66:2215-23.

22. Robinson JD. An interactional structure of medical activities during acute visits and its implications for patients' participation. Health Commun. 2003;15(1):27-59.

23. Heritage J, Robinson J. Accounting for the visit: giving reasons for seeking medical care. In: Heritage J, Maynard D, editors. Communication in medical care: Interactions between primary care physicians and patients. Cambridge: Cambridge University Press; 2006. p. 48-85.

24. Thaler RH, Sunstein CR. Nudge: improving decisions about health, wealth, and happiness. Cambridge: Yale University Press; 2008.

25. Stivers T. Non-antibiotic treatment recommendations: delivery formats and implications for parent resistance. Soc Sci Med. 2005;60(5):949-64.

26. Heritage J, Robinson JD. The structure of patients' presenting concerns: physicians opening questions. Health Commun. 2006;19(2):89-102.

27. Mangione-Smith R, Stivers T, Elliott MN, McDonald L, Heritage $\mathrm{J}$. The relationship between online commentary use and prevention of inappropriate antibiotic prescribing by pediatricians. Soc Sci Med. 2003;56:313-20.

28. Stivers T. "Symptoms only" versus "Candidate diagnoses": presenting the problem in pediatric encounters. Health Commun. 2002;14(3):299-338.

29. Mangione-Smith R, Zhou C, Robinson JD, Taylor JA, Elliott $\mathrm{MN}$, Heritage J. Communication practices and antibiotic use for acute respiratory tract infections in children. Ann Fam Med. 2015;13(3):221-7.

30. Stivers T, Timmermans S. Medical authority under siege: how clinicians transform patient resistance into acceptance. J Health Soc Behav. 2020;61(1):60-78.

31. Linder JA, Stafford RS. Antibiotic treatment of adults with sore throat by community primary care physicians: a national survey, 1989-1999. J Am Med Assoc. 2001;286(10):1181-6.

32. Fairlie T, Shapiro DJ, Hersh AL, Hicks LA. National trends in visit rates and antibiotics prescribing for adults iwth acute sinusitis. J Am Med Assoc. 2012;172(19):1513-4.

33. Ray MJ, Tallman GB, Bearden DT, Elman MR, McGregor JC. Antibiotic prescribing without documented indication in ambulatory care clinics: national cross sectional study. Br Med J. 2019;367:16461.

34. King LM, Lovegrove MC, Shehab N, Tsay S, Budnitz DS, Geller AI, et al. Trends in US outpatient antibiotic prescriptions during the coronavirus disease 2019 pandemic. Clin Infect Dis. 2021;73(3):e652-60. 